\title{
Perinatal Distress in Women in Low- and Middle-Income Countries: Allostatic Load as a Framework to Examine the Effect of Perinatal Distress on Preterm Birth and Infant Health
}

\author{
Shahirose Premji
}

Published online: 20 April 2014

(C) The Author(s) 2014. This article is published with open access at Springerlink.com

\begin{abstract}
In low- and middle-income countries (LMIC), determinants of women's and children's health are complex and differential vulnerability may exist to risk factors of perinatal distress and preterm birth. We examined the contribution of maternal perinatal distress on preterm birth and infant health in terms of infant survival and motherinfant interaction. A critical narrative and interpretive literature review was conducted. Peer-reviewed electronic databases (MEDLINE, Embase, Global Health, CINHAL), grey literature, and reference lists were searched, followed by a consultation exercise. The literature was predominantly from high-income countries. We identify determinants of perinatal distress and explicate changes in the
\end{abstract}

On behalf of MiGHT-Maternal Infant Global Health Team (Global collaborators in Research) [alphabetical order] Ms. Dorcas Akoya Amunga; Ms. Dorcus Asami Satia; Dr. Susan Dahinten; Dr. Farooq Ghani; Dr. Imtiaz Jehan; Dr. Zeenatkhanu Kanji; Mr. Adam King; Dr. Nicole Letourneau; Dr. Aliyah Mawji; Dr. Alliya Mohamed; Dr. Joseph Wangira Musana; Mrs. Mwasha Loveluck; Dr. Haider Ali Naqvi; Dr. Christopher T. Naugler; Ms. Christine Omukani Okoko; Dr. M. Sarah Rose; Dr. Pauline Samia; Ms. Kiran Shaikh; Ms. Salima Gulamani; Mr. Josephat Wambua; Ms. Saba Wasim; Dr. Ilona S. Yim.

S. Premji $(\square)$

Faculty of Nursing, University of Calgary, 2500 University

Drive NW, Calgary, AB T2N 1N4, Canada

e-mail: premjis@ucalgary.ca

S. Premji

Department of Community Health Sciences, Faculty of

Medicine, University of Calgary, TRW Building, 3rd Floor,

3280 Hospital Drive NW, Calgary, AB T2N 4Z6, Canada

S. Premji

Alberta Children's Hospital Research Institute, Heritage Medical

Research Building, 3300 Hospital Drive NW, Calgary,

AB T2N 1N4, Canada hypothalamic-pituitary-adrenal axis, sympathetic, immune and cardiovascular systems, and behavioral responses resulting in pathophysiological effects. We suggest cultural-neutral composite measures of allostatic mediators (i.e., several biomarkers) of maternal perinatal distress as objective indicators of dysregulation in body systems in pregnant women in LMIC. Understanding causal links of maternal perinatal distress to preterm birth in women in LMIC should be a priority. The roles of allostasis and allostatic load are considered within the context of the health of pregnant women and fetuses/newborns in LMIC with emphasis on identifying objective indicators of the level of perinatal distress and protective factors or processes contributing to resilience while facing toxic stress. We propose a prospective study design with multiple measures across pregnancy and postpartum requiring complex statistical modeling. Building research capacity through partnering researchers in high-income countries and LMIC and reflecting on unique ethical challenges will be important to generating new knowledge in LMIC.

Keywords Maternal stress - Pregnancy outcome - Infant, preterm $\cdot$ Allostatic load $\cdot$ Developing countries

\section{Introduction}

Both perinatal distress and preterm birth are world-wide problems that are especially burdensome in low- and middle- income countries (LMIC). Maternal prenatal and postnatal distress (i.e., stress, anxiety, or depression at any time in pregnancy and during the first year following birth of the infant), collectively referred to as "perinatal distress," may be significantly higher in LMIC than high income countries [1]. The prevalence of perinatal mental 
disorders reported for LMIC is comparable to certain highrisk groups of women living in high-income countries [13]. In LMIC the determinants of women's and children's health are complex. Moreover, inequities in determinants of health and the social, cultural, and political contexts of women in LMIC negatively influence women's mental health. Consequently, differential vulnerability may exist not only to risk factors of perinatal distress, but also to predictors of pregnancy outcome [4].

Stress, anxiety, or depression during pregnancy may contribute to preterm birth [5, 6]. Every year, 15 million babies are born prematurely, and 1.1 million will die due to prematurity-related health issues globally $[7,8]$. Twelve of the 15 countries which contribute more than $60 \%$ to the global burden of preterm birth are low or low-middle income countries [9]. Preterm birth is one of the major contributors to infant mortality and morbidity [7, 10], accounting for $80 \%$ of the world's 1.1 million deaths [9]. Africa and South Asia, with the exception of Pakistan, have made some progress in improving neonatal survival; however, death resulting from preterm birth is now the second leading cause of newborn deaths $[7,9]$. Up to $50 \%$ of pediatric neurodevelopment problems (e.g., cerebral palsy, lower intelligence quotient) are estimated to be the result of preterm birth [11-14].

Perinatal distress may also adversely influence infant survival, behavior, and development through poor quality of maternal-infant interactions [15-21]. A Taiwanese population-based study, that linked birth and death certificate registry, found the adjusted risk of mortality among preschool children up to age 5 years was 1.47 fold ( $95 \%$ Confidence Interval, CI 1.16-1.87) when mothers experienced depression in the first year following birth [22]. Infants born in LMIC are already exposed to poverty, poor health, and poor nutrition, which reduces their developmental potential [23]. Beyond these issues, infants of depressed mothers are less likely to be breastfed, have incomplete immunizations, have poorer weight gain, and are more likely to experience illnesses, such as diarrhea, which in turn, may increase the number of hospital admissions and contribute to higher mortality in children under 5 years of age [24-31].

Clinicians typically rely on self-report questionnaires to assess perinatal distress. While very useful, self-report is prone to bias or error [32]. An alternative is to use biomarkers that may offer a more objective and quantifiable indicator of the level of perinatal distress [33]. The conceptual framework of allostatic load [20] links perinatal distress and its physiological responses to multisystem dysregulation, which promotes a cascade of events ultimately impacting pregnancy outcome (i.e., preterm birth) and infant health (i.e., survival and development) $[16,18-$ $20,34]$. In this context, biomarkers that detect physiological compromise may be useful predictors of perinatal distress and its negative consequences. Specifically, perinatal distress may activate aspects of the hypothalamic-pituitary-adrenal (HPA) axis, sympathetic, immune and cardiovascular systems, and promote behavior changes (e.g., smoking, drinking) in the effort to restore allostasis $[13,20]$. Over time, given "wear and tear" on the brain and body, biological responses may be compromised, or fail outright. Allostasis refers to the continual changes in set points (i.e., lower or higher ranges) of physiologic systems to maintain constancy $[20,34]$ with repeated and ongoing (i.e., chronic) exposure to determinants of perinatal distress over the course of pregnancy $[16,35,36]$. The resulting dysregulation of interrelated systems may, over time, reach a "tipping-point" [16] referred to as allostatic load or overload, that ultimately results in pathophysiological effects. In the case of perinatal distress, effects can include preterm birth [20, 34] and altered maternal and infant behaviors that adversely influence infant survival and development [15, 16, 18-21, 37].

A critical narrative and interpretive review [38] was undertaken to: (a) determine the etiologic contribution of perinatal distress on preterm birth in pregnant women in LMIC; and (b) develop a conceptual framework that would explicate the potential casual links of perinatal distress to preterm birth and infant health (i.e., infant survival, and mother-infant interaction). The goal of the review was to inform future research in LMIC by providing a conceptual framework to examine psychosocial and environmental factors as both risk factors and targets of intervention to prevent preterm birth (i.e., improve maternal health outcomes) and improve infant survival and development.

\section{Methods}

\section{Search and Selection Strategy}

We searched peer-reviewed electronic databases including MEDLINE (1946-January 2013), Embase (1974-January 2013), Global Health (1910-January 2013), and Cumulative Index to Nursing and Allied Health Literature (CINHAL) (1990-January 2013). Grey literature (e.g., unpublished theses, organizational websites), reference lists, and an existing network of experts in the area (including research team members from Pakistan, Kenya, and Tanzania) were also used in identifying relevant publications. A conventional review technique using the search strategy and selection strategy detailed in Table 1 proved to be limiting given the dearth of literature in LMIC (see Figs. 1, 2). In contrast, a search of the existing literature using all key words, combined terms, and exclusion criteria (i.e., etiology and conceptual framework) without limiting the country of origin generated 6,908 records. 
Table 1 Key words, combined terms, and selection criteria

\begin{tabular}{|c|c|c|c|}
\hline & Key words & Combined terms & Selection criteria \\
\hline $\begin{array}{l}\text { Etiologic } \\
\text { contribution of } \\
\text { perinatal } \\
\text { distress on } \\
\text { preterm birth }\end{array}$ & $\begin{array}{l}\text { Stress; anxiety; depression; stress, } \\
\text { maternal; stress, psychological; } \\
\text { chronic stress; postpartum depression; } \\
\text { perinatal distress; or perinatal } \\
\text { depression }\end{array}$ & $\begin{array}{l}\text { Pregnancy; women; pregnant, women; } \\
\text { perinatal outcomes; infant health; infant } \\
\text { survival; mother-infant interaction; } \\
\text { maternal health; or preterm birth }\end{array}$ & $\begin{array}{l}\text { Pregnant or postpartum women; } \\
\text { recruitment in low- and middle- } \\
\text { income countries; assessed } \\
\text { psychosocial health/factors; } \\
\text { examined any determinant of } \\
\text { health that would impact maternal } \\
\text { psychosocial well-being and } \\
\text { maternal or infant health; any } \\
\text { study design; human; English }\end{array}$ \\
\hline $\begin{array}{l}\text { Conceptual } \\
\text { framework }\end{array}$ & Allostasis or allostatic load & Pregnancy; preterm birth; or brain & $\begin{array}{l}\text { Pregnant or postpartum women; } \\
\text { recruitment in low- and middle- } \\
\text { income countries; maternal health; } \\
\text { infant health; any study design; } \\
\text { human; English }\end{array}$ \\
\hline
\end{tabular}

Applying a precise review question or narrowing the search by assembling certain levels of evidence is restrictive when the intent of the literature review is also to generate a theory [38]. Consequently, we used a critical narrative and interpretive synthesis approach [38], based in dialectic process including both inductive and deductive reasoning, to guide our sampling of the extant literature, regardless of study type and

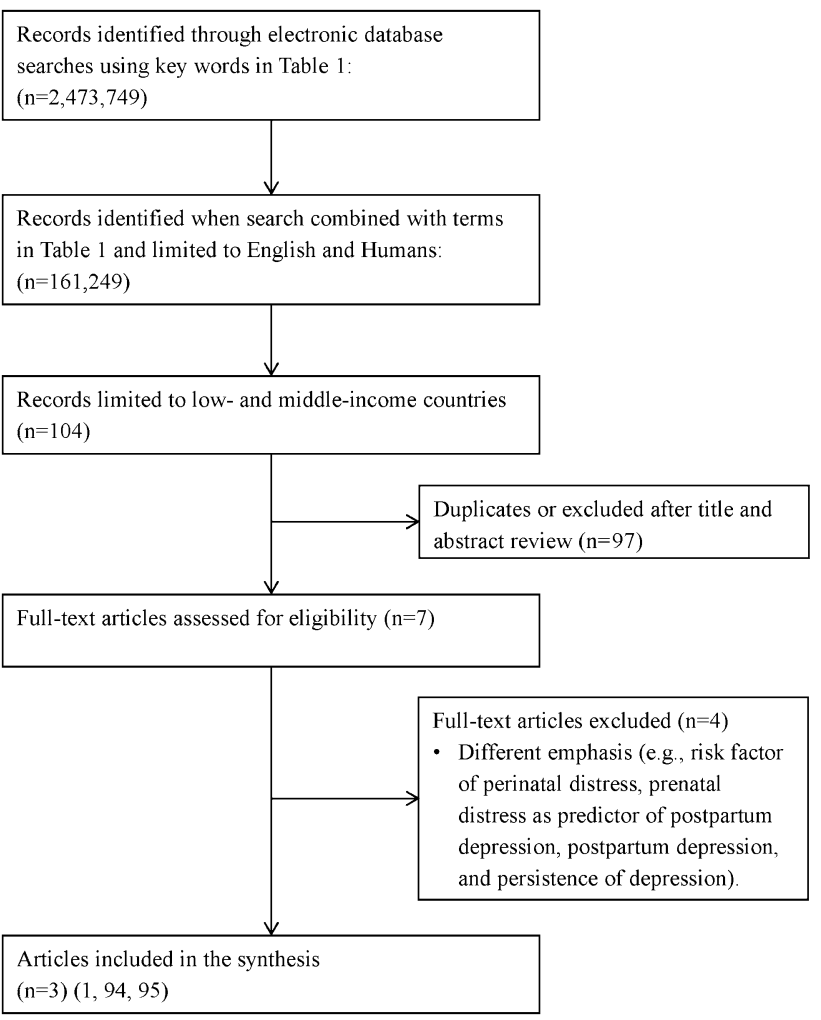

Fig. 1 Overview of trial flow through the search and selection process: Contribution of perinatal distress on preterm birth location of study, while maintaining a focus on the aims of the review. As a starting point we used our earlier review [39] on the relationship between prenatal stress, depression, cortisol and preterm birth, and the literature reviewed here. We then purposefully sampled the existing literature to elaborate on the phenomena of interest and our analysis of the literature. The approach we used to develop the conceptual framework was iterative and the emphasis of the review changed and was informed by our emerging understanding and analysis of the literature (i.e., recursive and reflexive). We continued to sample the literature until there was saturation, that is, similar ideas emerged repeatedly [38]. A total of 73 articles identified through this iterative process complemented the eight articles identified in the initial search (see Figs. 1, 2).

\section{Quality Assessment and Data Extraction}

All types of studies were valued for their contribution, as they provided new ways of understanding our emergent conceptual framework and causal links between perinatal distress and preterm birth. Criteria for assessment included: (1) whether the study design was appropriate given the aim and objectives of the study; (2) appraisal of study reporting (e.g., data collection process described, appropriate method of analysis, enough data shared to support interpretation and conclusions); or (3) judgment about whether the study clarified what is known and what is not known, and informed the interpretation of concepts or the review in general [38]. No papers were removed because of poor methodological standards.

\section{Consultation Exercise}

Towards the end of the review, a group of stakeholders (researchers, clinicians, academics, and policy decisionmakers) from Pakistan, Kenya, Tanzania, and Canada were 


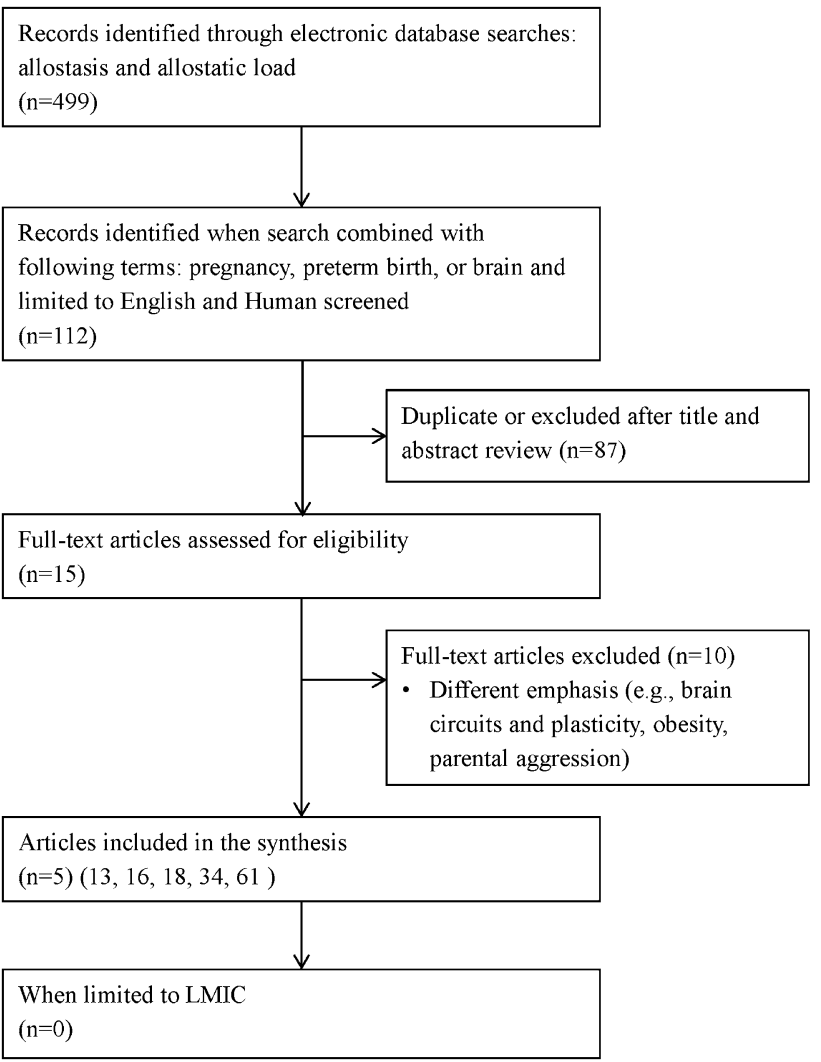

Fig. 2 Overview of trial flow through the search and selection process: Allostasis and allostatic load

brought together to add additional insights and refine the conceptual framework. Terminology, such as perinatal distress, was clarified and a common understanding was developed of concepts. Essential elements of the framework were identified and revisions were made to better illustrate relationships between components. Through an iterative and consensus building process with feedback received from peer-reviewers of this manuscript, we present the final conceptual framework (see Fig. 3).

\section{Findings}

Perinatal mental health of women living in LMIC, particularly mental health during pregnancy, received little attention until 2002. LMIC were represented in only 8 and $15 \%$ of the pregnant- and post-partum related studies, respectively compared to $90 \%$ of high income countries $[1,40]$. A systematic review [1] and a report of the World Health Organization-United Nations Population Fund [40] concluded that available literature from LMIC (41 studies) suggests a wide range in prevalence rates of perinatal mental disorders as a consequence of place of recruitment (e.g., tertiary hospital, provincial or district health services, and community facilities), and methodology (e.g., time of data collection, and screening instruments). An average prevalence of $15.9 \%$ (95\% CI 15.0-16.8\%) during pregnancy and $19.8 \%$ (95\% CI 19.2-20.6\%) postpartum were reported [1], with depression and anxiety disorders being the most frequent diagnoses in both periods $[1,40]$. The conceptual framework to examine risk factors for perinatal distress varied among the 31 studies and therefore data could not be pooled [1]. Findings related to risk and protective factors of perinatal distress were mixed and the majority did not address all the domains of the social determinants of health used to synthesize the literature, namely, socioeconomic factors, quality of relationship with intimate partner, family and social relationships, reproductive and general health, history of mental health problems, and infant characteristics [1]. Social factors, particularly those beyond the women's control, seem to influence perinatal mental health of women in LMIC [1]. Moreover, prevention of preterm birth has received little attention in these countries. Although we were able to identify nine studies focusing on preterm birth in LMIC, none examined the relationship between perinatal distress and preterm birth. Five studies [7-10] reviewed epidemiology including global trends, causes, and interventions thus informed this review. However, four studies were excluded as they focused on the use of antenatal steroids in LMIC (two studies), or long-term neurodevelopmental outcomes of preterm infants born in LMIC (two studies). Thus, in LMIC there are missed opportunities to address mental health needs of women along the perinatal continuum and contribute to scientific knowledge and evidenceinformed practices and policies to reduce preterm birth and improve infant health outcomes.

\section{Perinatal Distress Predicts Preterm Birth}

The term "perinatal distress" encompasses a spectrum of psychological conditions in response to experiences of episodic and chronic stress associated with adverse socioeconomic, cultural, and environmental phenomena [41]. The North American literature suggests that pregnancyrelated anxiety, which relates to the women's fears about the infant's health, delivery, her own health and survival during the birthing experience, and the impending responsibility of providing for the child [42], is a stronger determinant of preterm birth than general anxiety [5, 6, 4244]. Though many North American and European studies have shown an association between general anxiety and preterm birth (e.g., $[45,46])$, the findings have been mixed (e.g., $[47,48])$. In one study, changes in anxiety level over time rather than the anxiety level at one time point predicted preterm birth [49]. North American and European studies examining the relationship between depression and preterm birth have also shown inconsistent findings, with a 


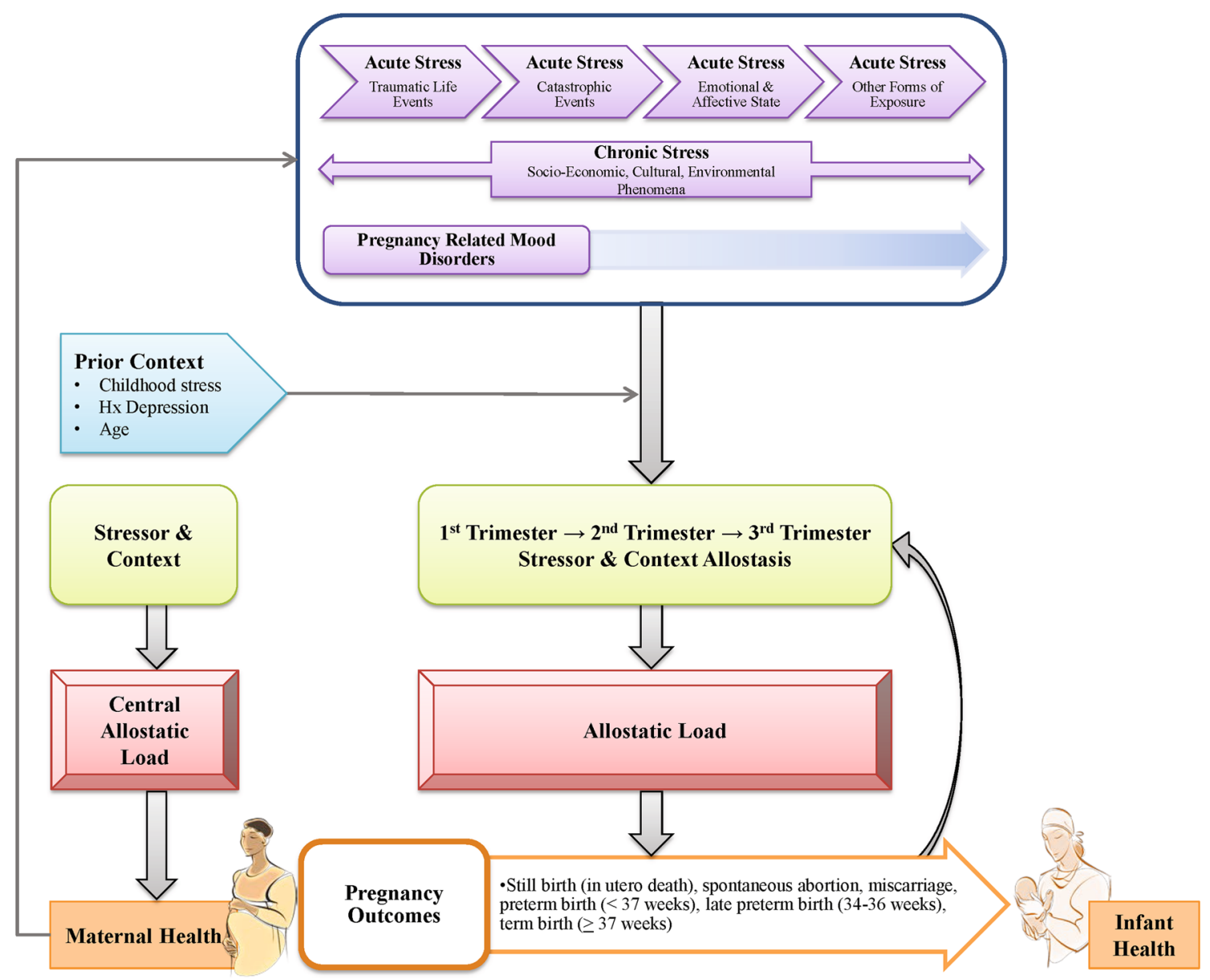

Fig. 3 Perinatal distress and pathways to pregnancy outcome: Allostatic load as a conceptual framework

minority of the studies finding a statistically significant association between depression and preterm birth (e.g., [44, 46, 50]).

Many distinguishable forms of stress can be grouped into chronic stressors and episodic (i.e., acute) stressors. Chronic stress differs from acute stress, in that the threat or demand is long-lived, and often without resolution [13]. The chronic stress of homelessness or household strain has been associated with preterm birth [41]. A study of 739 low-income African-American pregnant women in the United States found that inadequacy of time and money for non-essentials (e.g., time to look nice, time with friends and family) were mediating factors for preterm birth, whereas multidimensional stress (money worries, family problems, and neighborhood crime) and locus of control were independent predictors of preterm birth [51]. Neighborhood-level stressors, such as poverty, crime, and racial composition have also shown an independent impact on preterm birth [41]. Episodic stressors include catastrophic events, such as natural disasters (e.g., hurricane, earthquake, and drought), and manmade calamities (e.g., political strife, and war), have shown varied impacts on pregnancy outcomes from no detected effect (e.g., [52]), to lower [53] and higher [54] rates of preterm birth. The inconsistent findings may be explained by differences in levels of support, medical care, and changes in behavior following the event [41].

Based on the current literature, a multidimensional approach for examining perinatal distress is evident. None of the studies located examined all of the above dimensions of perinatal distress in relation to preterm birth in the same sample. Whether perinatal distress predicts preterm birth in LMIC remains to be established, as none of the studies considered women in LMIC despite nine of the 11 countries with the highest rate of preterm birth being LMIC [9]. In our pilot study [55] the odds of preterm birth were 1.44 times higher in the depressed Pakistani women than in the non-depressed Pakistani women. The social, cultural, and environmental context of LMIC provide the potential for an in-depth investigation of the multidimensional nature of perinatal distress, which could not be achieved in highincome countries, as all dimensions of perinatal distress coexist in one setting. Furthermore, the void of empirical literature stemming from LMIC on perinatal distress makes 
it imperative to examine the etiologic contribution of perinatal distress on preterm birth in LMIC.

\section{Explaining Causal Links of Perinatal Distress to Preterm Birth}

In an attempt to adapt or maintain stability (i.e., allostasis), the body responds to perinatal distress (i.e., stress, anxiety, or depression) by producing multisystem physiologic responses through the production of hormonal and neurotransmitter mediators [20, 56, 57]. In addition to being protective or adaptive, these mediators can have damaging effects [58]. Over time, repeated fluctuations and elevated levels of physiologic activity can lead to inefficiency in allostasis where accumulation and overexposure to these mediators (i.e., allostatic load) may results in organ system failure [56, 58]. According to the conceptual framework of allostatic load, composite measures of biomarkers (i.e., hormonal and neurotransmitter mediators) versus individual biomarkers may be a stronger predictor of negative consequences of perinatal distress [56, 59]. The original set of ten parameters of allostatic load continues to expand [60]. Empirically supported allostatic load biomarkers implicated in the pathophysiological process linking perinatal distress to preterm birth include:

\section{Cortisol}

The brain coordinates the interconnected set of neuroendocrine and behavioral responses to perinatal distress [58, 61]. Cortisol, regulated via the HPA axis, is a primary hormone reported to be elevated in response to stress induced by physical, cognitive and psychosocial challenges [58, 61]. Cortisol is also proposed to be a primary mediator contributing to allostatic load $[59,61]$. Although chronically high levels of cortisol have been the focus in the interplay between stress and allostatic load, low cortisol has also been implicated in adverse health outcomes [61]. Consequently, response and recovery promoting optimal functioning of pathophysiologic processes following stress is important when considering allostatis [61]. Thus, low values and high values may be predictive of preterm birth. Cortisol, measured in blood, has been reported in the majority of studies to have a positive association with preterm birth [62].

\section{Corticotropin-Releasing Hormone}

Pathologic levels of cortisol can increase the production of placental corticotropin-releasing hormone (CRH) in a dose response relationship [63]. Placental CRH levels beyond a certain threshold can have a paradoxical effect of preparing for labor and initiating contractions [63]. In the pregnant state, the diurnal variations in hormones, such as cortisol, are to a certain extent diminished [34]. In an attempt to compensate for the dysregulation of cortisol, systemic responses of the metabolic, inflammatory, and cardiovascular systems may also experience dysregulation [36, 64].

\section{Triglyceride, Total Cholesterol, Low-Density Lipoprotein, and High-Density Lipoprotein}

Total cholesterol, and high-density lipoprotein (HDL), represent the primary effects in response to dysregulation of cortisol [59]. Hypercholesterolemia (a secondary mediator) may result in response to high levels of cortisol which mobilizes lipids from adipose tissues [65]. Although high levels of cholesterol decreases uterine contractility [65], in combination with the natural lipid profile of pregnancy [66], an allostatic load effect may alter the vulnerability of the uterine smooth muscle thereby changing its propensity to remain quiescent during pregnancy. During pregnancy, the lipid profile of women changes (i.e., increase in triglyceride, total cholesterol, and low-density lipoprotein) in response to hormonal changes occurring with increasing gestational age [66]. Alternation in lipid metabolism, specifically delayed clearance of triglycerides, has been implicated in pregnancy complications (e.g., hypertension and development of preeclampsia) that may lead to medically indicated preterm birth [66], as well as adverse pregnancy and infant outcomes [67].

\section{White Blood Cell Count, C-Reactive Protein, and Cytokines}

Primary effects, such as changes in inflammatory biomarkers in response to primary neuromediators (i.e., cortisol) of stress, have been implicated in the pathway to preterm birth. A systematic review examining the association between inflammatory cytokines and risk of spontaneous preterm birth in asymptomatic women concluded that the maternal-fetal interface, rather than systemic inflammation, plays a major role [68]. Pregnancy-related anxiety has been associated with preterm birth [6, 69], but among these two studies, only one found that inflammatory markers mediated this influence [69]. Various scales were used to measure pregnancy-related anxiety and samples were drawn from high-income countries with low rates of preterm birth.

Immunosuppression of cellular and humoral immune activity resulting from dysregulation of neuroendocrine mediators, is either site specific (e.g., bacterial vaginosis) [70] or systemic, and may increase risk of infections which may be monitored by examining changes in white blood cells counts. In a meta-analysis, bacterial vaginosis was identified as a strong risk factor for preterm birth, with individual studies repeatedly and consistently 
demonstrating an association [70]. A connection has also been demonstrated between prenatal stress and C-reactive protein (CRP) [69]. Increased inflammatory cytokines produced both in response to stress (primary mediators) and in response to the infection stimulates production of CRP and triggers prostaglandin production which is a mediator of labor [71]. Typically increased cortisol levels serve as a negative feedback loop to decrease production of cytokines and hormones [71]; however, the dysregulation of neuromediators most likely impairs this negative feedback loop.

\section{Immunoglobulin $G$}

Immunoglobulin $\mathrm{G}$, an antibody that crosses the placenta, is critical in protecting the infant from infection in the neonatal period. Lower transplacental ratios of immunoglobulin $\mathrm{G}$ have been reported in preterm infants [72]. High levels of immunoglobulin $\mathrm{G}$, in response to dysregulation of cortisol, is proposed to saturate binding sites, thereby limiting the placenta's efficiency in transfer of immunoglobulin G [73]. Since the infant's humoral response is inefficient, the impaired transfer of immunoglobulin $\mathrm{G}$ may further compromise the infant's ability to fight infection in early life [73] and increase risk of mortality.

\section{Blood Pressure and Heart Rate}

Increased blood pressure and heart rate represent a disease state or disorders resulting from allostatic load, as a consequence of secondary outcomes and primary mediator of stress [59]. Cardiovascular reactivity is normally reduced in pregnancy [74]. However, increased levels of cortisol may increase maternal cardiovascular reactivity (e.g., increase blood pressure and heart rate-secondary mediators) [34] by altering maternal, placental or fetal hemodynamics [75]. A relationship has been demonstrated between high diastolic blood pressure responses to stress during pregnancy and decreased gestational age at birth [75-78]. A dose-response pattern has been observed between the rise in blood pressure and spontaneous preterm birth [79].

There is empirical support (approximately 60 studies) for an association between increased allostatic load and negative health consequences of stress (e.g., cardiovascular disease) [80]. Notably, none of the documented studies (e.g., [6, 55, 81-85]) examining the relationship between perinatal distress, biomarkers of stress, and preterm birth have made use of allostatic load in their conceptual framework. Moreover, the scales used to measure perinatal distress, biomarkers of stress examined, time periods of measurements and findings have varied between studies (see Table 2). Individual mediators of stress examined in these studies included cytokines (interleukin-10, interleukin-6 and tumor necrosis factor-alpha), CRP [69], cortisol [6], and CRH [6]. Interrelated physiological (i.e., biochemical) response patterns [86, 87] and composite measures involving several biochemical measures offer a more objective and quantifiable indicator of the level of perinatal distress in pregnant women in LMIC who are in difficult cultures, than self-report psychological measures of perinatal distress $[56,59]$. The risk of preterm birth will be higher when there is an inadequate response to prenatal distress (i.e., high perinatal distress and low allostatic load) or prolonged response to a previous stress (i.e., low perinatal distress and high allostatic load) [20, 57]. Identifying high risk pregnant women in LMIC and understanding the pathophysiological process of poor pregnancy and health outcomes will guide the development and evaluation of therapeutic interventions to avert preterm birth.

\section{Explaining Causal Links of Perinatal Distress to Infant Health}

Allostatic load or overload exerts its influence on biological indices or mediators of the HPA axis and sympatheticadrenal-medullary systems involving a complex interplay between the mother and fetus [13, 59]. The dysregulation of cortisol influences the permeability of the placenta to cortisol, thereby altering the placental and fetal environment [64] and potentially increasing permeability of other mediators which typically do not cross the placenta (e.g., epinephrine). The health of the fetus and newborn "mirror" the health of the mother whereby the fetus or newborn mimics the biochemical profile of the mother. Allostatic load in the fetal brain may also alter behavioral systems which involve attachment/approach and avoidance behaviors that are integral to survival $[16,18,58]$. Allostatic load may also alter the function (e.g., affective, cognitive, and social) and structure of the brain, and pathological levels may impact developmental outcomes [19]. Perinatal distress may directly (e.g., alter structure and function of brain) or indirectly (i.e., through mother-infant interaction) influence infant health and well-being.

In addition to activating the HPA axis, and sympathetic, immune and cardiovascular systems, psychosocial health during pregnancy has been linked to negative maternal health behavior (e.g., consuming non-nutritive substances like soil, consumption of alcohol, and cigarette smoking) [88]. Maternal prenatal distress and postnatal distress may result in the same disorders simply manifested along the perinatal continuum [89]. Altered parenting patterns (i.e., lack of responsivity to infants' needs [90, 91], inability to coordinate age-appropriate activities [92], and harsh parenting style [93] ) observed in mothers with PPD may contribute to infant stress, with cumulative stress influencing vulnerability to death, disease, or poor 


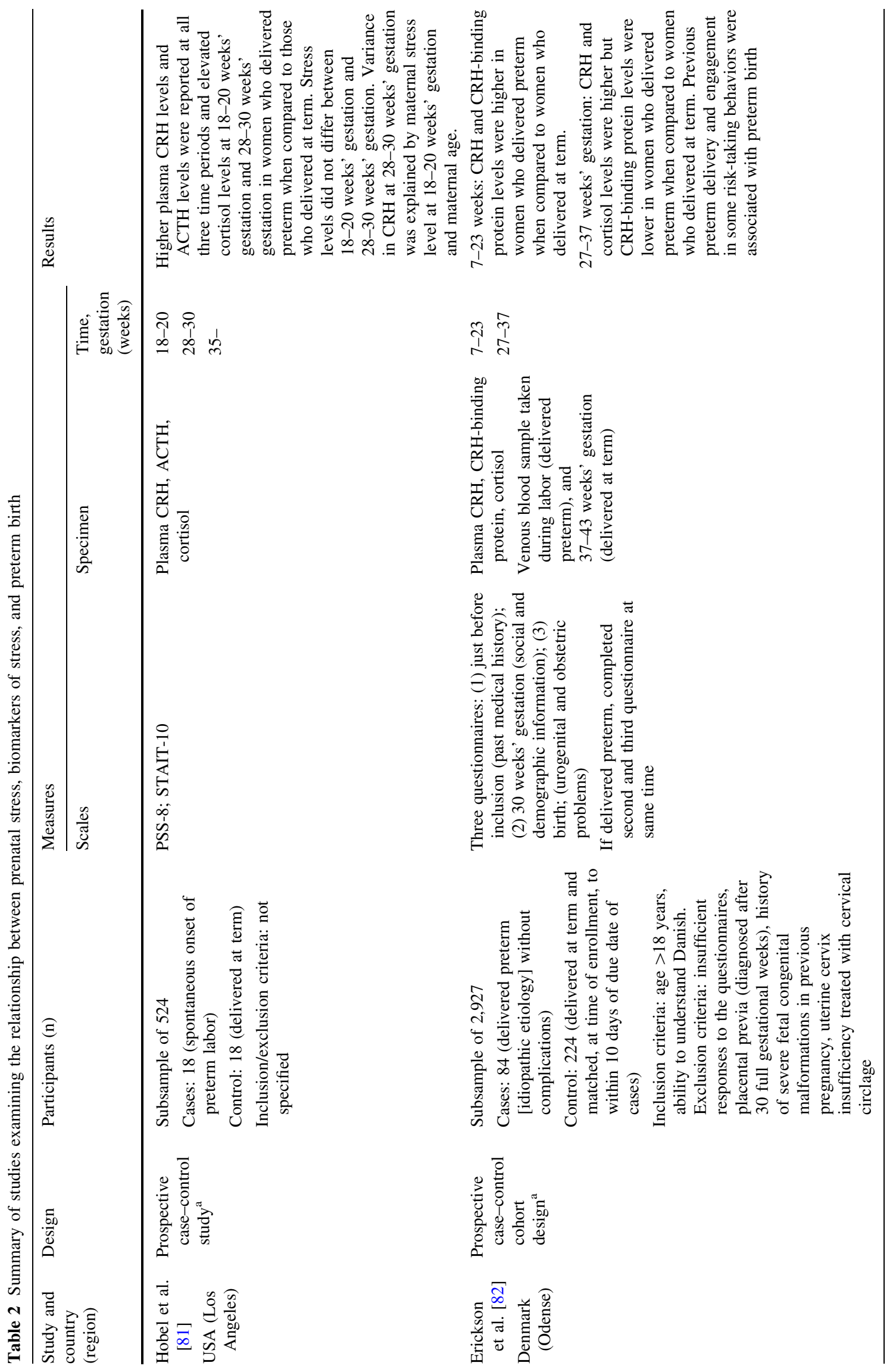




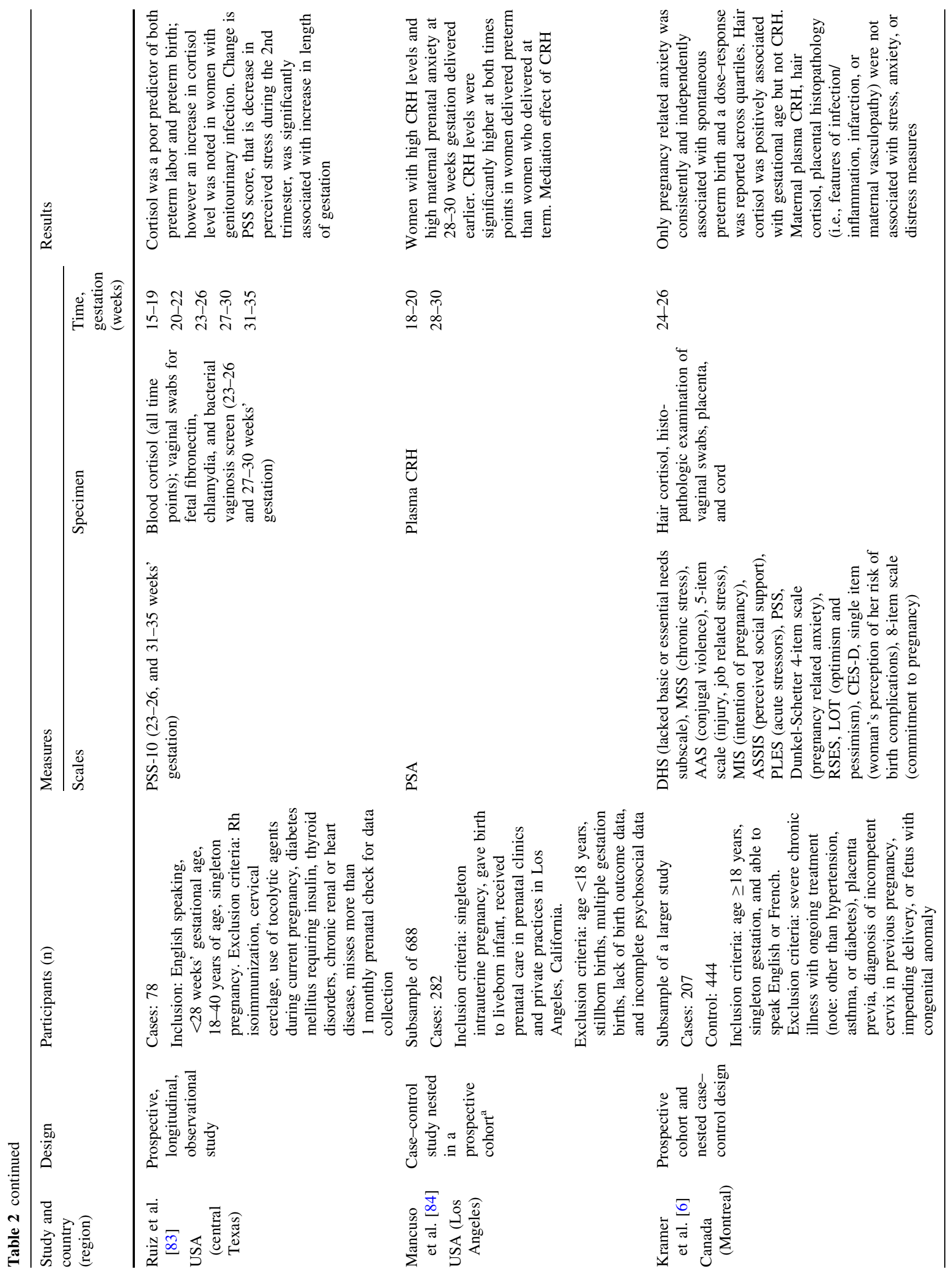




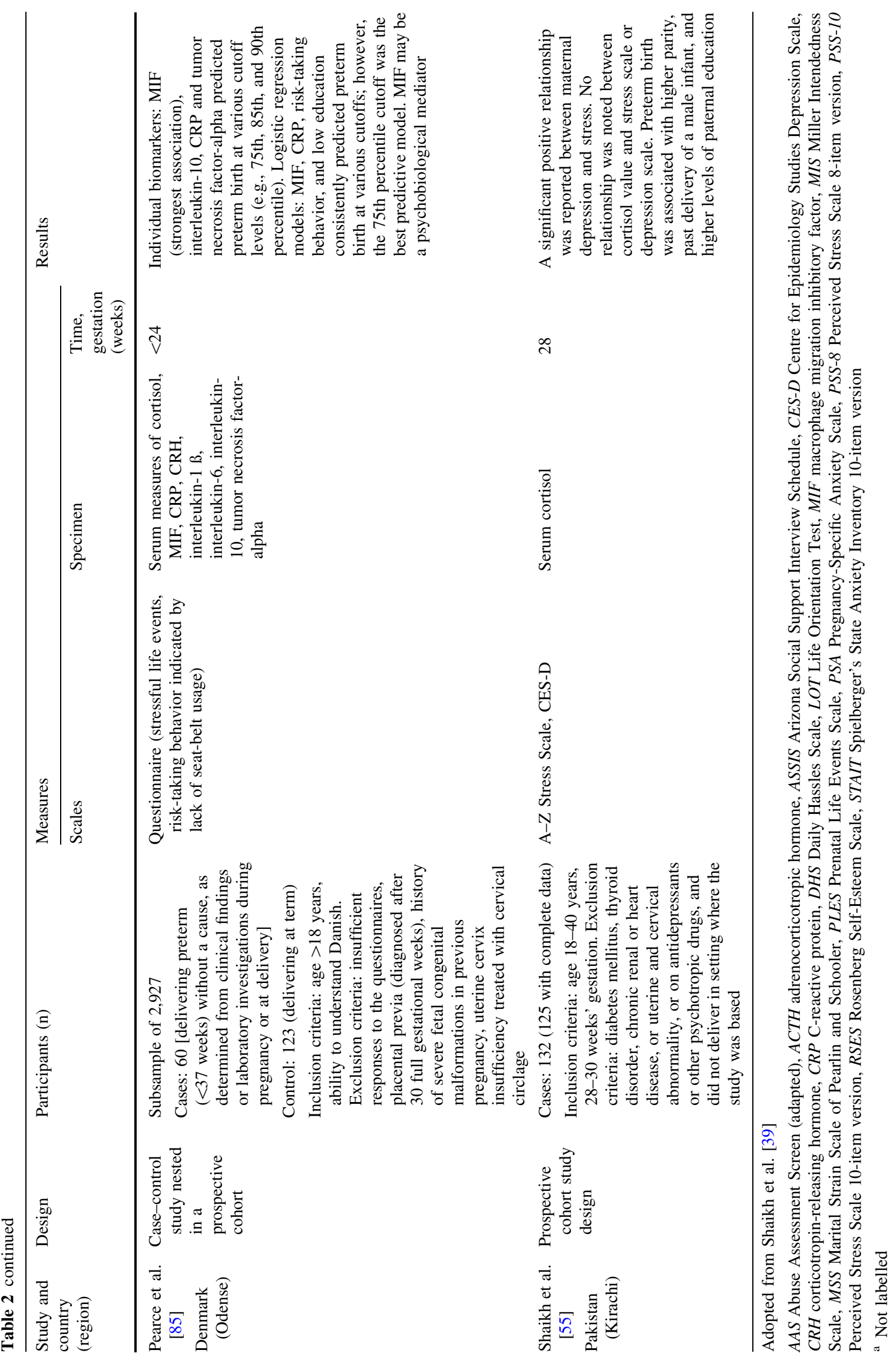


developmental outcomes through the effects of infant allostatic load [15-21]. Although in LMIC there is limited evidence examining the contribution of prenatal distress to infant health outcomes (e.g., [94]), there is extensive scientific evidence linking PPD and infant health [95] that may be explained by the conceptual framework of allostatic load.

Our pilot data suggests that the odds of depression are 2.7 times greater (95\% CI 1.16-6.17, $p=0.015)$ in Pakistani mothers of preterm infants than Pakistani mothers of full-term infants [96]. Thus, for infants born in LMIC, the interactive effects of biological vulnerability associated with being born premature, social vulnerability inherent in women's responses to their environment during the postpartum period and inequities in determinants of health (i.e., poverty, poor nutrition) places them at triple jeopardy to experience poorer health outcomes. In LMIC, premature infants' chance of survival, well-being and lifetime developmental and behavioral success may depend on reducing or managing risk factors associated with perinatal distress. For example, implementing early interventions to reduce the risk of stress, anxiety or depression during pregnancy or improve maternal behavior (i.e., increase responsiveness to infant) in the months following the birth of the infant may be warranted.

\section{Discussion}

The conceptual framework of allostatic load relates preterm birth to the social, environmental, and biological antecedent of perinatal distress, thereby enabling researchers to examine the interrelationships between various determinants of health. It provides an integrated model that is essential to examine the nature of risk (i.e., cumulative risk) across many systems at the same time and the temporal effects of the risk(s). The use of the conceptual framework of allostatic load to examine the etiologic contributions of perinatal distress on pregnancy and infant outcomes will necessitate longitudinal study designs with multiple time points (e.g., first trimester, early and late second trimester, and third trimester), and multiple measures of data collection (i.e., all dimensions of perinatal distress).

Although for our purpose we have focused on the negative pregnancy outcome of preterm birth, the conceptual model can be used to investigate pathways for positive pregnancy outcomes. A positive health focus may facilitate population level interventions directed at promoting mental health during pregnancy or "salutogenesis" within the context of their social, cultural, and political environment [97]. In LMIC, focusing on what makes women resilient in the face of toxic stress (i.e., pervasive, uncontrollable stress)-that is, improving their sense of coherence or "way of being in the world" [98] - may reduce the burden of health care service delivery. Furthermore, this type of research will facilitate identification of culture-sensitive strategies [98] to promote the mental health of women along the perinatal continuum. However, it will be important to debate and discuss social and cultural norms and policies that undermine, both at an individual level and society level, women's mental health during pregnancy and postpartum and access to mental health services.

Building research capacity will be essential to addressing the under-representation of pregnancy and post-partum related studies in LMIC. Facilitating partnerships between researchers in high-income countries and LMIC to identify and resolve unique challenges related to ethical conduct of research will be important to generating new knowledge in LMIC. Key among these challenges is the communication and understanding of informed consent [99]. Since women in LMIC are underprivileged (e.g., poor, with limited access to health care), they may be particularly vulnerable to coercion. Moreover, in keeping with the World Medical Association Declaration of Helsinki, the research should "be responsive to the health needs and priorities of this population or community" [100]. Since mental health care services may be nonexistent or limited and predominantly hospital based [101] consideration should be given to developing or strengthening local mental health care referral services that will continue to serve the women after completion of the study. Strategies (e.g., referrals) will need to be developed to minimize risk and prevent harm to women participating in the study over the course of their pregnancy and following birth of their baby.

Aside from these ethical issues, studies involving blood sampling for allostatic load parameters need to critically consider the available laboratory infrastructure. Study procedures including procurement of laboratory samples, storage, transportation and processing may create technical and logistical difficulties. Establishing standard procedures, training and supervision of local researchers to develop research capacity, and assisting with knowledge transfer may mitigate logistical issues and ensure adherence to study protocols [102, 103]. Furthermore, quality assurance measures may need to be established to ensure quality data [104]. Recruitment and retention of subjects may present significant challenges [105] as infrastructure, including communication to arrange follow-up visits and clinical facilities for care may be lacking [102].

\section{Conclusion}

Pregnant women in LMIC have been a neglected population in studies on perinatal distress and pregnancy and infant outcomes. Given inequities in determinants of health and the social, cultural, and political contexts of childbearing women 
in LMIC, these women may experience differential vulnerability to risk factors for perinatal distress and poor pregnancy outcomes. Prospective studies with multiple biological and psychosocial measures of stress, depression or depressive symptoms and its antecedents (e.g., childhood stress, major life events, etc.), state and trait anxiety, and pregnancy-related anxiety may add new knowledge and enhance our understanding about the etiologic contributions of psychosocial processes to preterm birth. A theoretical framework of allostatic load will enable researchers to concurrently examine social, environmental, and genetic antecedents of stressrelated vulnerability and physiological (e.g., immune system, placenta) and behavioral responses that influence not only pregnancy outcomes of women in LMIC but also the life trajectories of health and wellness of the fetuses/infants (i.e., mortality and morbidity over time) [64]. Interrelated physiological (i.e., biochemical) response patterns [86, 87] and composite measures involving several biochemical measures offer a more objective and quantifiable indicator of the level of perinatal distress in pregnant women in LMIC. We propose that researcher maintain a positive health focus by identifying protective factors or processes that contribute to resilience in the face of toxic stress. When planning research studies using an integrative approach with both biological and psychosocial measures in LMIC, of critical importance is the adherence to principles of ethical conduct of research, engaging local researchers and other stakeholders to anticipate operational challenges to conducting research, and ensuring that the research is responsive to the needs of women during the perinatal period.

Acknowledgments We would like to thank the Canadian Institute for Health Research for supporting the planning meeting (reference number 264531), which supported the conceptualization of the framework to guide our research project entitled "Biomarkers of allostatic load in LMIC pregnant women: perinatal distress, preterm birth, and infant health". We would like to thank the Aga Khan University, School of Nursing and Midwifery, Karachi for hosting this planning meeting and Ms. Rozina Shazad, Dr. Saleem Iqbal and Ms. Rose Swai for participating in the planning meeting. A special thanks to Jill Norris for providing technical assistance in the preparation of the manuscript.

Open Access This article is distributed under the terms of the Creative Commons Attribution License which permits any use, distribution, and reproduction in any medium, provided the original author(s) and the source are credited.

\section{References}

1. Fisher, J., Cabral de Mello, M., Patel, V., Rahman, A., Tran, T., Holton, S., et al. (2012). Prevalence and determinants of common perinatal mental disorders in women in low- and lowermiddle-income countries: A systematic review. Bulletin of the World Health Organization, 90(2), 139G-149G.
2. Price, S. K., \& Proctor, E. K. (2009). A rural perspective on perinatal depression: Prevalence, correlates, and implications for help-seeking among low-income women. The Journal of Rural Health, 25(2), 158-166.

3. Gress-Smith, J. L., Luecken, L. J., Lemery-Chalfant, K., \& Howe, R. (2012). Postpartum depression prevalence and impact on infant health, weight, and sleep in low-income and ethnic minority women and infants. Maternal and Child Health Journal, 16(4), 887-893.

4. Denton, M., Prus, S., \& Walters, V. (2004). Gender differences in health: A Canadian study of the psychosocial, structural and behavioural determinants of health. Social Science and Medicine, 58(12), 2585-2600.

5. Dunkel Schetter, C., \& Tanner, L. (2012). Anxiety, depression and stress in pregnancy: Implications for mothers, children, research, and practice. Current Opinion in Psychiatry, 25(2), 141-148.

6. Kramer, M. S., Lydon, J., Séguin, L., Goutlet, L., Kahn, S. R., McNamara, H., et al. (2009). Stress pathways to spontaneous preterm birth: The role of stressors, psychological distress, and stress hormones. American Journal of Epidemiology, 169(11), 1319-1326.

7. Lawn, J. E., Gravett, M. G., Nunes, T. M., Rubens, C. E., Stanton, C., \& GAPPS Review Group. (2010). Global report on preterm birth and stillbirth ( 1 of 7): Definitions, description of the burden and opportunities to improve data. BMC Pregnancy Childbirth, 10(Suppl 1), S1.

8. Gann, C. (2012). Premature birth endangers $15 \mathrm{M}$ babies worldwide. ABC News. May 3. http://abcnews.go.com/blogs/ health/2012/05/03/premature-birth-endangers- $15 \mathrm{~m}$-babiesworldwide/.

9. March of Dimes, PMNCH, Save the Children, WHO. (2012). Born too soon: The global action report on preterm birth. In C. P. Howson, M. V. Kinney, J. E. Lawn, (Eds.), Written report. World Health Organization: Geneva. http://whqlibdoc.who.int/ publications/2012/9789241503433_eng.pdf.

10. Lawn, J. E., Wilczynska-Ketende, K., \& Cousens, S. N. (2006). Estimating the causes of 4 million neonatal deaths in the year 2000. International Journal of Epidemiology, 35(3), 706-718.

11. Goldenberg, R. L., Culhane, J. F., Iams, J. D., \& Romero, R. (2008). Epidemiology and causes of preterm birth. Lancet, 371(9606), 75-84.

12. Green, N. S., Damus, K., Simpson, J. L., Iams, J., Reece, E. A., Hobel, C. J., et al. (2005). Research agenda for preterm birth: Recommendations from the March of Dimes. American Journal of Obstetrics and Gynecology, 193(3 Pt 1), 626-635.

13. Latendresse, G. (2009). The interaction between chronic stress and pregnancy: Preterm birth from a biobehavioral perspective. Journal of Midwifery \& Women's Health, 54(1), 8-17.

14. Rafati, S., Borna, H., Akhavirad, M.-B., \& Fallah, N. (2005). Maternal determinants of giving birth to low-birth-weight neonates. Archives of Iranian Medicine, 8(4), 277-281.

15. Beck, C. T. (1998). The effects of postpartum depression on child development: A meta-analysis. Archives of Psychiatric Nursing, 12(1), 12-20.

16. Ganzel, B. L., Morris, P. A., \& Wethington, E. (2010). Allostasis and the human brain: Integrating models of stress from the social and life sciences. Psychological Review, 117(1), 134-174.

17. Grace, S. L., Evindar, A., \& Stewart, D. E. (2003). The effect of postpartum depression on child cognitive development and behavior: A review and critical analysis of the literature. Archives of Women's Mental Health, 6(4), 263-274.

18. Howell, B. R., \& Sanchez, M. M. (2011). Understanding behavioral effects of early life stress using the reactive scope and allostatic load models. Development and Psychopathology, 23(4), 1001-1016. 
19. Huizink, A. C., Robles de Medina, P. G., Mulder, E. J., Visser, G. H., \& Buitelaar, J. K. (2003). Stress during pregnancy is associated with developmental outcome in infancy. Journal of Child Psychology and Psychiatry, 44(6), 810-818.

20. McEwen, B. S., \& Wingfield, J. C. (2003). The concept of allostasis in biology and biomedicine. Hormones and Behavior, 43(1), 2-15.

21. Monk, C., Spicer, J., \& Champagne, F. (2012). Linking prenatal maternal adversity to developmental outcomes in infants: The role of epigenetic pathways. Development and Psychopathology, 24(4), 1361-1376.

22. Chen, Y. H., Tsai, S. Y., \& Lin, H. C. (2011). Increased mortality risk among offspring of mothers with postnatal depression: A nationwide population-based study in Taiwan. Psychological Medicine, 41(11), 2287-2296.

23. Grantham-McGregor, S., Cheung, Y. B., Cueto, S., Glewwe, P., Richter, L., Strupp, B., et al. (2007). Developmental potential in the first 5 years for children in developing countries. Lancet, 369(9555), 60-70.

24. Rahman, A., Lovel, H., Bunn, J., Iqbal, Z., \& Harrington, R. (2004). Mothers' mental health and infant growth: A casecontrol study from Rawalpindi, Pakistan. Child: Care, Health and Development, 30(1), 21-27.

25. Adewuya, A. O., Fatoye, F. O., Ola, B. A., Ijaodola, O. R., \& Ibigbami, S. M. (2005). Sociodemographic and obstetric risk factors for postpartum depressive symptoms in Nigerian women. Journal of Psychiatric Practice, 11(5), 353-358.

26. Adewuya, A. O., Ola, B. O., Aloba, O. O., Mapayi, B. M., \& Okeniyi, J. A. (2008). Impact of postnatal depression on infants' growth in Nigeria. Journal of Affective Disorders, 108(1-2), 191-193.

27. World Health Organization. (2009). Maternal mental health and child health and development in resource-constrained settings. Report of a UNFPA/WHO international expert meeting: The interface between reproductive health and mental health, Hanoi, June 21-23, 2007. World Health Organization Document Production Services: Geneva. WHO/RHR/09.24. http://whqlibdoc. who.int/hq/2009/WHO_RHR_09.24_eng.pdf.

28. Black, M. M., Baqui, A. H., Zaman, K., El Arifeen, S., \& Black, R. E. (2009). Maternal depressive symptoms and infant growth in rural Bangladesh. American Journal of Clinical Nutrition, 89(3), 951S-957S.

29. Rahman, A., Iqbal, Z., Bunn, J., Lovel, H., \& Harrington, R. (2004). Impact of maternal depression on infant nutritional status and illness: A cohort study. Archives of General Psychiatry, 61(9), 946-952.

30. Rahman, A., Patel, V., Maselko, J., \& Kirkwood, B. (2008). The neglected ' $\mathrm{m}$ ' in $\mathrm{MCH}$ programmes-Why mental health of mothers is important for child nutrition. Tropical Medicine \& International Health, 13(4), 579-583.

31. Rahman, A., Bunn, J., Lovel, H., \& Creed, F. (2007). Maternal depression increases infant risk of diarrhoeal illness: A cohort study. Archives of Disease in Childhood, 92(1), 24-28.

32. Cohen $\mathrm{S}$ in collaboration with the Psychosocial Working Group. (2013). Measures of psychological stress [Internet]. The Regents of the University of California: San Franscisco, CA [revised February 2000; cited 2013 June 2]. http://www.macses.ucsf.edu/ research/psychosocial/stress.php.

33. Mayeux, R. (2004). Biomarkers: Potential uses and limitations. NeuroRx, 1(2), 182-188.

34. Shannon, M., King, T. L., \& Kennedy, H. P. (2007). Allostasis: A theoretical framework for understanding and evaluating perinatal health outcomes. Journal of Obstetric, Gynecologic, \& Neonatal Nursing, 36(2), 125-134.

35. Cicchetti, D. (2011). Allostatic load. Development and Psychopathology, 23(3), 723-724.
36. Juster, R. P., McEwen, B. S., \& Lupien, S. J. (2010). Allostatic load biomarkers of chronic stress and impact on health and cognition. Neuroscience and Biobehavioral Reviews, 35(1), $2-16$.

37. Grace, S. L., Evindar, A., \& Stewart, D. E. (2003). The effect of postpartum depression on child cognitive development and behavior: A review and critical analysis of the literature. Archives of Women's Mental Health, 6(4), 263-274.

38. Dixon-Woods, M., Cavers, D., Agarwal, S., Annandale, E., Arthur, A., Harvey, J., et al. (2006). Conducting a critical interpretive synthesis of the literature on access to healthcare by vulnerable groups. BMC Medical Research Methodology, 6, 35.

39. Shaikh, J., Premji, S., Khowaja, K., Tough, S., Kazi, A., \& Khowaja, S. (2013). The relationship between prenatal stress, depression, cortisol and preterm birth: A review. Open Journal of Depression, 2(3), 24-31.

40. UNFPA and World Health Organization, Department of Mental Health and Substance Abuse. (2008). Maternal mental health and child health and development in low and middle income countries: Report of the meeting held in Geneva, Switzerland, 30 January-1 February, 2008. World Health Organization: Geneva. NLM classification: WS 105.5.F2. http://www.who.int/ mental_health/prevention/suicide/mmh_jan08_meeting_report. pdf.

41. Dunkel Schetter, C., \& Glynn, L. M. (2011). Stress in pregnancy: Empirical evidence and theoretical issues to guide interdisciplinary researchers. In R. Contrada \& A. Baum (Eds.), Handbook of stress (pp. 321-343). New York: Springer.

42. Dunkel Schetter, C. (2011). Psychological science on pregnancy: Stress processes, biopsychosocial models, and emerging research issues. Annual Review of Psychology, 62, 531-558.

43. Dole, N., Savitz, D. A., Hertz-Picciotto, I., Siega-Riz, A. M., McMahon, M. J., \& Buekens, P. (2003). Maternal stress and preterm birth. American Journal of Epidemiology, 157(1), 14-24.

44. Orr, S. T., James, S. A., \& Blackmore Prince, C. (2002). Maternal prenatal depressive symptoms and spontaneous preterm births among African-American women in Baltimore, Maryland. American Journal of Epidemiology, 156(9), 797-802.

45. Goldenberg, R. L., Cliver, S. P., Mulvihill, F. X., Hickey, C. A., Hoffman, H. J., Klerman, L. V., et al. (1996). Medical, psychosocial, and behavioral risk factors do not explain the increased risk for low birth weight among black women. American Journal of Obstetrics and Gynecology, 175(5), 1317-1324.

46. Dayan, J., Creveuil, C., Herlicoviez, M., Herbel, C., Baranger, E., Savoye, C., et al. (2002). Role of anxiety and depression in the onset of spontaneous preterm labor. American Journal of Epidemiology, 155(4), 293-301.

47. Andersson, L., Sundstrom-Poromaa, I., Wulff, M., Astrom, M., \& Bixo, M. (2004). Neonatal outcome following maternal antenatal depression and anxiety: A population-based study. American Journal of Epidemiology, 159(9), 872-881.

48. Dominguez, T. P., Schetter, C. D., Mancuso, R., Rini, C. M., \& Hobel, C. (2005). Stress in African American pregnancies: Testing the roles of various stress concepts in prediction of birth outcomes. Annals of Behavioral Medicine, 29(1), 12-21.

49. Glynn, L. M., Schetter, C. D., Hobel, C. J., \& Sandman, C. A. (2008). Pattern of perceived stress and anxiety in pregnancy predicts preterm birth. Health Psychology, 27(1), 43-51.

50. Jesse, D. E., Seaver, W., \& Wallace, D. C. (2003). Maternal psychosocial risks predict preterm birth in a group of women from Appalachia. Midwifery, 19(3), 191-202.

51. Misra, D. P., O’Campo, P., \& Strobino, D. (2001). Testing a sociomedical model for preterm delivery. Paediatric and Perinatal Epidemiology, 5(2), 110-122. 
52. Engel, S. M., Berkowitz, G. S., Wolff, M. S., \& Yehuda, R. (2005). Psychological trauma associated with the World Trade Center attacks and its effect on pregnancy outcome. Paediatric and Perinatal Epidemiology, 19(5), 334-341.

53. Rich-Edwards, J. W., Kleinman, K. P., Strong, E. F., Oken, E., \& Gillman, M. W. (2005). Preterm delivery in Boston before and after September 11th, 2001. Epidemiology, 16(3), 323-327.

54. Xiong, X., Harville, E. W., Mattison, D. R., Elkind-Hirsch, K., Pridjian, G., \& Buekens, P. (2008). Exposure to Hurricane Katrina, post-traumatic stress disorder and birth outcomes. The American Journal of the Medical Sciences, 336(2), 111-115. (Erratum in: Am J Med Sci 2011;341(1):85).

55. Shaikh, K., Premji, S. S., Rose, M. S., Kazi, A., Khowaja, S., \& Tough, S. (2011). The association between parity, infant gender, higher level of paternal education and preterm birth in Pakistan: A cohort study. BMC Pregnancy Childbirth, 11, 88.

56. Seeman, T. E., Singer, B. H., Rowe, J. W., Horwitz, R. I., \& McEwen, B. S. (1999). Price of adaptation-allostatic load and its health consequences. Archives of Internal Medicine, 157(19), 2259-2268. (Erratum in: Arch Intern Med 1999;159(11):1176).

57. McEwen, B., Nasveld, P., Palmer, M., Anderson, R., \& (Centre for Military, Veterans' Health). (2012). Allostatic Load: A review of the literature. Canberra: Department of Veterans' Affairs.

58. McEwen, B. S. (2006). Protective and damaging effects of stress mediators: Central role of the brain. Dialogues in Clinical Neuroscience, 8(4), 367-381.

59. Seeman, T. E., McEwen, B. S., Rowe, J. W., \& Singer, B. H. (2001). Allostatic load as a marker of cumulative biological risk: MacArthur studies of successful aging. Proceedings of the National Academy of Sciences, 98(8), 4770-4775.

60. Bellingrath, S., Weigl, T., \& Kudielka, B. M. (2009). Chronic work stress and exhaustion is associated with higher allostastic load in female school teachers. Stress, 12(1), 37-48.

61. Badanes, L. S., Watamura, S. E., \& Hankin, B. L. (2011). Hypocortisolism as a potential marker of allostatic load in children: Associations with family risk and internalizing disorders. Development and Psychopathology, 23(3), 881-896.

62. Giurgescu, C. (2009). Are maternal cortisol levels related to preterm birth? Journal of Obstetric, Gynecologic, and Neonatal Nursing, 38(4), 377-390.

63. Wadhwa, P. D., Garite, T. J., Porto, M., Glynn, L., ChiczDeMet, A., Dunkel-Schetter, C., et al. (2004). Placental corticotropin-releasing hormone (CRH), spontaneous preterm birth, and fetal growth restriction: A prospective investigation. American Journal of Obstetrics and Gynecology, 191(4), 1063-1069.

64. Beckie, T. M. (2012). A systematic review of allostatic load, health, and health disparities. Biological Research for Nursing, 14(4), 311-346.

65. Lowe, N. K., \& Corwin, E. J. (2011). Proposed biological linkages between obesity, stress, and inefficient uterine contractility during labor in humans. Medical Hypotheses, 76(5), $755-760$.

66. Ekhator, C. N., \& Ebomoyi, M. I. (2012). Blood glucose and serum lipid profiles during pregnancy. African Journal of Diabetes Medicine, 20(1), 16-19.

67. Vrijkotte, T. G., Krukziener, N., Hutten, B. A., Vollebregt, K. C., van Eijsden, M., \& Twickler, M. B. (2012). Maternal lipid profile during early pregnancy and pregnancy complications and outcomes: The ABCD study. Journal of Clinical Endocrinology and Metabolism, 97(11), 3917-3925.

68. Wei, S. Q., Fraser, W., \& Luo, Z. C. (2010). Inflammatory cytokines and spontaneous preterm birth in asymptomatic women: A systematic review. Obstetrics and Gynecology, 116(2 Pt 1), 393-401.
69. Coussons-Read, M. E., Lobel, M., Carey, J. C., Kreither, M. O., D'Anna, K., Argys, L., et al. (2012). The occurrence of preterm delivery is linked to pregnancy-specific distress and elevated inflammatory markers across gestation. Brain, Behavior, and Immunity, 26(4), 650-659.

70. Leitich, H., Bodner-Adler, B., Brunbauer, M., Kaider, A., Egarter, C., \& Husslein, P. (2003). Bacterial vaginosis as a risk factor for preterm delivery: A meta-analysis. American Journal of Obstetrics and Gynecology, 189(1), 139-147.

71. Gennaro, S., \& Hennessy, M. D. (2003). Psychological and physiological stress: Impact on preterm birth. Journal of Obstetric, Gynecologic, and Neonatal Nursing, 32(5), 668-675.

72. van den Berg, J. P., Westerbeek, E. A., Berbers, G. A., van Gageldonk, P. G., van der Klis, F. R., \& van Elburg, R. M. (2010). Transplacental transport of IgG antibodies specific for pertussis, diphtheria, tetanus, haemophilus influenzae type $b$, and Neisseria meningitidis serogroup $\mathrm{C}$ is lower in preterm compared with term infants. The Pediatric Infectious Disease Journal, 29(9), 801-805.

73. Palmeira, P., Quinello, C., Silveira-Lessa, A. L., Zago, C. A., \& Carneiro-Sampaio, M. (2012). IgG placental transfer in healthy and pathological pregnancies. Clinical and Developmental Immunology, 2012, 985646.

74. de Weerth, C., \& Buitelaar, J. K. (2005). Physiological stress reactivity in human pregnancy-A review. Neuroscience and Biobehavioral Reviews, 29(2), 295-312.

75. McCubbin, J. A., Lawson, E. J., Cox, S., Sherman, J. J., Norton, J. A., \& Read, J. A. (1996). Prenatal maternal blood pressure response to stress predicts birth weight and gestational age: A preliminary study. American Journal of Obstetrics and Gynecology, 175(3 Pt 1), 706-712.

76. Gomez de Ponce, R., Gomez Ponce de Leon, L., Coviello, A., \& De Vito, E. (2001). Vascular maternal reactivity and neonatal size in normal pregnancy. Hypertens Pregnancy, 20(3), 243-256.

77. Hatch, M., Berkowitz, G., Janevic, T., Sloan, R., Lapinski, R., James, T., et al. (2006). Race, cardiovascular reactivity, and preterm delivery among active-duty military women. Epidemiology, 17(2), 178-182.

78. Hilmert, C. J., Dominquez, T. P., Schetter, C. D., Srinivas, S. K., Glynn, L. M., Hobel, C. J., et al. (2014). Lifetime racism and blood pressure changes during pregnancy: Implications for fetal growth. Health Psychology, 33(1), 43-51.

79. Zhang, J., Villar, J., Sun, W., Merialdi, M., Abdel-Aleem, H., Mathai, M., et al. (2007). Blood pressure dynamics during pregnancy and spontaneous preterm birth. Am J Obstet Gynecol, 197(2), 162.e1-162.e6.

80. Juster, R. P., \& Lupien, S. (2012). A sex- and gender-based analysis of allostatic load and physical complaints. Gender Medicine, 9(6), 511-523.

81. Hobel, C. J., Dunkel-Schetter, C., Roesch, S. C., Castro, L. C., \& Arora, C. P. (1999). Maternal plasma corticotropin-releasing hormone associated with stress at 20 weeks' gestation in pregnancies ending in preterm delivery. American Journal of Obstetrics and Gynecology, 180(1 Pt 3), S257-S263.

82. Erickson, K., Thorsen, P., Chrousos, G., Grigoriadis, D. E., Khongsaly, O., McGregor, J., et al. (2001). Preterm birth: Associated neuroendocrine, medical, and behavioral risk factors. Journal of Clinical Endocrinology and Metabolism, 86(6), 2544-2552.

83. Ruiz, R. J., Fullerton, J., Brown, C. E., \& Schoolfield, J. (2001). Relationships of cortisol, perceived stress, genitourinary infections, and fetal fibronectin to gestational age at birth. Biological Research for Nursing, 3(1), 39-48.

84. Mancuso, R. A., Schetter, C. D., Rini, C. M., Roesch, S. C., \& Hobel, C. J. (2004). Maternal prenatal anxiety and corticotropin- 
releasing hormone associated with timing of delivery. Psychosomatic Medicine, 66(5), 762-769.

85. Pearce, B. D., Grove, J., Bonney, E. A., Bliwise, N., Dudley, D. J., Schendel, D. E., et al. (2010). Interrelationship of cytokines, hypothalamic-pituitary-adrenal axis hormones, and psychosocial variables in the prediction of preterm birth. Gynecologic and Obstetric Investigation, 70(1), 40-46.

86. Shapiro, G. D., Fraser, W. D., Frasch, M. G., \& Séguin, J. R. (2013). Psychosocial stress in pregnancy and preterm birth: Associations and mechanisms. Journal of Perinatal Medicine, 41(6), 631-645.

87. Halbreich, U. (2005). The association between pregnancy processes, preterm delivery, low birth weight, and postpartum depressions-The need for interdisciplinary integration. American Journal of Obstetrics and Gynecology, 193(4), $1312-1322$.

88. Young, S. L. (2010). Pica in pregnancy: New ideas about an old condition. Annual Review of Nutrition, 30, 403-422.

89. Hayes, B. A. (2010). From 'postnatal depression' to 'perinatal anxiety and depression': Key points of the National Perinatal Depression Plan for nurses and midwives in Australian primary health care settings. Contemporary Nurse, 35(1), 58-67.

90. Beck, C. T. (2001). Predictors of postpartum depression: An update. Nursing Research, 50(5), 275-285.

91. Feldman, R., \& Eidelman, A. I. (2006). Neonatal state organization, neuromaturation, mother-infant interaction, and cognitive development in small-for-gestational-age premature infants. Pediatrics, 118(3), e869-e878.

92. Oehler, J. M., Hannan, T., \& Catlett, A. (1993). Maternal views of preterm infants' responsiveness to social interaction. Neonatal network: $N N, 12(6), 67-74$.

93. Bugental, D. B., \& Happaney, K. (2004). Predicting infant maltreatment in low-income families: The interactive effects of maternal attributions and child status at birth. Developmental Psychology, 40(2), 234-243.

94. Ross, J., Hanlon, C., Medhin, G., Alem, A., Tesfaye, F., Worku, B., et al. (2011). Perinatal mental distress and infant morbidity in Ethiopia: A cohort study. Archives of Disease in ChildhoodFetal and Neonatal Edition, 96(1), F59-F64.

95. Parsons, C. E., Young, K. S., Rochat, T. J., Kringelbach, M. L., \& Stein, A. (2012). Postnatal depression and its effects on child development: A review of evidence from low- and middleincome countries. British Medical Bulletin, 101(1), 57-79.
96. Gulamani, S. S., Premji, S. S., Kanji, Z., \& Azam, S. I. (2013). Preterm birth a risk factor for postpartum depression in Pakistani women. Open Journal of Depression, 2(4), 72-81.

97. Lindstrom, B., \& Eriksson, M. (2005). Salutogenesis. Journal of Epidemiology and Community Health, 59(6), 440-442.

98. Benyamin, M., Hadar, S., \& Asher, S. (2011). Culture-sensitive therapy and salutogenesis: Treating Israeli Bedouin of the Negev. International Review of Psychiatry, 23(6), 550-554.

99. Gikonyo, C., Bejon, P., Marsh, V., \& Molyneux, S. (2008). Taking social relationships seriously: Lessons learned from the informed consent practices of a vaccine trial on the Kenyan Coast. Social Science and Medicine, 67(5), 708-720.

100. World Medical Association. (2008). World Medical Association declaration of Helsinki: Ethical principles for medical research involving human subjects [Internet]. 59th WMA General Assembly Seoul, October 2008, pp. 1-5. http://www.wma.net/ en/30publications/10policies/b3/index.html.

101. Saxena, S., Lora, A., Morris, J., Berrino, A., Esparza, P., Barrett, T., et al. (2011). Mental health services in 42 low- and middleincome countries: A WHO-AIMS cross national analysis. Psychiatric Services, 62(2), 123-125.

102. Marchetti, E., Mazarin-Diop, V., Chaumont, J., Martellet, L., Makadi, M. F., Viviani, S., et al. (2012). Conducting vaccine clinical trials in sub-Saharan Africa: Operational challenges and lessons learned from the Meningitis Vaccine Project. Vaccine, 30(48), 6859-6863.

103. Lang, T. A., White, N. J., Tran, H. T., Farrar, J. J., Day, N. P., Fitzpatrick, R., et al. (2010). Clinical research in resource-limited settings: Enhancing research capacity and working together to make trials less complicated. PLoS Neglected Tropical Diseases, 4(6), e619.

104. Mbuagbaw, L., Thabane, L., Ongolo-Zogo, P., \& Lang, T. (2011). The challenges and opportunities of conducting a clinical trial in a low resource setting: The case of the Cameroon mobile phone SMS (CAMPS) trial, an investigator initiated trial. Trials, 12, 145.

105. Padayatchi, N., Mac Kenzie, W. R., Hirsch-Moverman, Y., Feng, P. J., Villarino, E., Saukkonen, J., et al. (2012). Lessons from a randomised clinical trial for multidrug-resistant tuberculosis. The International Journal of Tuberculosis and Lung Disease, 16(12), 1582-1587. 